Research Paper:

\title{
The Relationship Between Personality Traits and General crossuark Health of Nursing Students
}

\author{
Mahnaz Seyedoshohadaee $^{1^{*}}$,Muhammad Hossain Hakimi ${ }^{1}$, Marjan Mardani ${ }^{2}$, Hameed Baqaee ${ }^{3}$ \\ 1. Department of Medical Surgical Nursing, School of Nursing and Midwifery, Iran University of Medical Sciences, Tehran, Iran. \\ 2. Department of Psychiatric Nursing, School of Nursing and Midwifery, Iran University of Medical Sciences, Tehran, Iran \\ 3. Department of Biostatistics, School of Public Health, Iran University of Medical Sciences, Tehran, Iran.
}

Article info:

Received: 14 Mar. 2016

Accepted: 23 Jul. 2016
Citration: Seyedoshohadaee, M. et al., 2017. The Relationship Between Personality Traits and General Health of Nursing Students. Journal of Client-Centered Nursing Care, 3(1), pp. 11-18. https://doi.org/10.32598/jccnc.3.1.11

: https://doi.org/10.32598/jcenc.3.1.11
Keywords:

Nursing, Student, Personality trait, General health

\begin{abstract}
A B S T RA C T
Background: Students' general health is of great importance and serious attention should be paid to their health-related issues. Some personal characteristics such as their traits may be the most influential factors in their general health. Thus, the current study was conducted to determine the relationship between personal traits and general health in nursing students.

Methods: This is a descriptive correlational research which was conducted on 194 undergraduate nursing students of Qom Medical University, Qom, Iran, in 2015. Samples were chosen by census method. The relevant data were collected by demographic information, the shortened form of five personality traits assessment, and general health questionnaires. The data were analyzed using Pearson correlation and t-tests by SPSS V. 23.
\end{abstract}

Results: A significant positive correlation was found between personality traits of extraversion, agreeableness, conscientiousness and general health, while there was a significant negative correlation between neuroticism and general health. Also with regard to general health domains, the maximum mean (SD) belonged to social dysfunction with 8.72 (3.420), and the minimum to depression with 3.27 (4.368). Study results indicated that maximum score belonged to conscientiousness and minimum to neuroticism among the personality traits.

Conclusion: Since personality traits play an influential role in different aspects of students general health, it is expected that factors affecting nursing students' general health be paid more attention and appropriate training for raising health services for students be planned and provided.

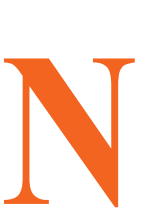

\section{Background}

ursing students' general health is of great importance and serious attention should be paid to their health-related issues (Moal- lemi, Bakhshani \& Raghibi 2011). Some psychological factors such as individual traits may affect students' academic achievement (Ghorbani et al. 2013). In fact, these features which a person is equipped with as a result of confronting with different situations and people, produce

\section{* Corresponding Author:}

Mahnaz Seyedoshohadaee, MSc.

Address: Department of Medical Surgical Nursing, School of Nursing and Midwifery, Iran University of Medical Sciences, Tehran, Iran. Tel: +98 (912) 2979750

E-mail: seyedoshohadaee.m@iums.ac.ir 
his or her psychological construct and personality traits. This psychological construct is not only influenced by various factors such as the family, peer group, and so on, but also influences some other factors (Barry, Lakey \& Orehek 2007). Individual traits are the influential factors in students' growth and their personal development (Hasanpour, Haghdoost-Oskouie \& Salsalei 2005). Based on the five factor personality model, personality comprised 5 traits, including neuroticism, extraversion, agreeableness, conscientiousness, and openness to experience (Golestanbagh et al. 2016). Neuroticism is a personality trait whose one end is high emotional stability and low anxiety, and another end low emotional stability and high anxiety (Chamorro-Premuzic \& Furnham 2009). Extroverted people tend to influence their environment and compete with others. Individuals with experimental openness personality trait seek new experiences in their lives. Agreeable ones tend to trust, cooperate, and support others and conscientious ones are purposeful and determined (Fortunato \& Furey 2009).

Komarraju, Karau and Schmeck (2009) studied the relationship between personality traits and predicting motivation and academic achievements among 308 undergraduate students. Their findings showed a positive correlation between personality traits of conscientiousness, openness to experience, and agreeableness with achievement and motivation, but no correlation between personality traits of neuroticism and extraversion with achievement motivation.

Furthermore, students are exposed to different types of anxiety such as being far away from their families, economic problems, lack of interest in the field they were accepted in, and academic problems, which endanger their general health (Horney et al. 2014; McGready \& Brookmeyer 2013). Medical students, including nursing ones, due to their field of study and hard work conditions they have in hospitals in direct contact with patients, are in danger of health problems (Sotodeh et al. 2014). That is why it is critical to pay attention to the nursing students' health. Those who are responsible for the health of the society (Block et al. 2013), and efforts for improving the students' quality of life help both their lives and society (Khansanami et al. 2015).

Nursing students, due to the nature of their profession, are generally in close contact with clients who are in need of strong psychological support; a good nurse is capable of proper professional communication besides having scientific information and clinical efficacy (Ghorbani et al. 2013). In this regard, it is essential to care for their health status as future builders of society.
Regarding the poor consideration paid to the role of personality traits in factors related to general health and no conducted study on the relationship between personality traits and general health in the nursing students, as the future builders of the society, especially in male and female students separately, and also the different culture of Qom compared to other cities, which affects students' cultural and religious conditions and their quality of lives, the researcher conducted a research to determine the relationship between personality traits with nursing students' general health and their quality of life at Qom University of Medical Sciences.

\section{Materials \& Methods}

\section{Design and sample}

This is a descriptive correlational study conducted in 2015. The sample and population was the same in this study, and census method was used for selecting samples. Research sample was the nursing students, freshmen to seniors, at Qom University of Medical Sciences. To determine the sample size, we set to have $95 \%$ confidence interval, $80 \%$ power, and a correlation coefficient (r) of each personality traits with general health as 0.2 or more, to be statistically significant. The sample size was estimated to be at least 194 participants.

\section{Data collection}

The shortened form of five personality traits assessment questionnaire, called NEO-FFI, which is a 60-item questionnaire to assess 5 basic personality traits, namely, neuroticism, extraversion, openness to experience, agreeablenss, and conscientiousness (each with 12 questions) was used to collect data. Questions were rated according to 5-point Likert-type Scale as $4=$ completely disagree, $3=$ disagree, $2=$ no idea, $1=$ agree, and $0=$ completely agree. This tool measures 5 aspects of character. Five subscores are obtained from all personality traits, then the sum is categorized and interpreted in the ranges of 12-24, 25-48, and 49-60. Since no one was in the range of 49-60, this part was omitted from the related table by the permission taken from statistics scholar.

The questionnaire validity coefficients ranged from 0.53 to 0.64 , which was at the significant level of $\mathrm{P} \leq$ 0.01 ; its reliability by test-retest in 5 domains of neuroticism, extraversion, openness to experience, agreeableness, and conscientiousness were 0.81, 0.73, 0.75, 0.79, and 0.83 , respectively (Zare' \& Mohammadzadeh 2012).

General Health Questionnaire (GHQ) was designed to determine the non-psychotic disorders. This 28-item 
questionnaire is the short form of 60-item which is suitable for research activities and distinguishing healthy people from unhealthy ones. The questions consider each participant's mental status during the last month. This 28-item general health questionnaire consists of 4 sub-tests, each with 7 questions. The questions in each sub-test come successively, in a way that questions 1-7 relates to physical symptoms, 8-14 to anxiety and insomnia, 15-21 to social dysfunction, and 22-28 to depression. Physical symptoms sub-test considers general health and physical symptoms each individual experiences during the last month. Regarding anxiety and insomnia sub-test, the symptoms related to severe anxiety, feeling pressure, anger, anxiety, insomnia and panic were examined.

Social dysfunction sub-test estimates individual's capability in conducting everyday tasks, his or her decision making power, satisfaction of performing one's duties, feeling to be useful in life, and enjoying daily activities. And finally depression sub-test evaluates symptoms of depression, including feelings of hopelessness, and worthlessness of life; having suicidal ideations and dying intention; feelings of worthlessness; and inability to do things. Each item in general health questionnaire has 4 options: not at all, usual, often, and very often. Scoring was done based on 4-point Likert-type scale $(0,1,2,3)$. According to this method, the total score is at least 0 and at most 84 . Generally, the score 23 or lower indicate desirable health, and 23 or more present undesirable health and having a symptom. Since the score was from 0 to 84 , lower score indicate better mental health.

The validity and reliability of GHQ-28 was determined in Noorbala, Bagheri Yazdi and Mohamad (2009) study, entitled "validation of general health 28 -item questionnaire as a tool for screening psychiatric disorders." The concurrent validity of the questionnaire with the Symptom Checklist-90-Revised (SCL-90-R) showed significant correlation between participants' scores in subscales of both questionnaires; so that bivariate Pearson correlation coefficient for subscale of anxiety in both GHQ-28 and SCL-90-R was 0.75; for complaints and physical symptoms 0.67 ; and for depression 0.72 . The correlations of scales for physical symptoms, anxiety, social dysfunction, and depression with total score of GHQ-28 was 0.80 , $0.92,0.75$, and 0.88 , respectively. Test-retest method was used to determine the reliability of GHQ-28; i.e. samples were re-evaluated one week after the first implementation, whose correlation was 0.85 . After taking permission for research from the University Research Ethics Committee at Iran University of Medical Science, obtaining introductory letter from Research Vice Chancellor, and getting informed consent from research participants, who were freshmen to senior nursing students with no known mental and emotional disorders, the researcher distributed the questionnaires and then collected them being answered after 24 to 48 hours.

\section{Data analysis}

The data were analyzed by descriptive and inferential tests. All collected data were analyzed by SPSS V. 23 doing descriptive statistics, t-test, analysis of variance, and correlation coefficient. P-values less than 0.05 were considered as statistically significant.

\section{Results}

The study participants were 114 girls and 80 boys and their Mean (SD) age was 21.49 (2.98) years. Among personality traits, the maximum score belonged to conscientiousness with the Mean (SD) score of 32.48 (6.795), and the minimum to neuroticism with 21.38 (5.791) (Table 1).

The findings indicated that total Mean (SD) score of nursing students' general health was 23.48 (9.151), with at least 6 and at most 54 points. Moreover, most students (58.8\%) had desirable health (Table 2). Regarding the domains related to general health, the maximum Mean (SD) belonged to social dysfunction for 8.72 (3.420), and the minimum Mean (SD) to depression for 3.27 (4.368) (Table 2).

The results of the Pearson test indicated a positive significant correlation between extraversion $(\mathrm{P}<0.001, \mathrm{r}$ $=0.308)$, agreeableness $(\mathrm{P}<0.001, \mathrm{r}=0.285)$, conscientiousness $(\mathrm{P}<0.001, \mathrm{r}=0.351)$ and students' general health; also a negative significant correlation between neuroticism and students' general health $(\mathrm{P}<0.001, \mathrm{r}=$ $-0.381)$, and no correlation between openness to experience and students' general health $(\mathrm{P}=0.249, \mathrm{r}=0.083)$ (Table 3). Furthermore, analysis of variance indicated a significant correlation between neuroticism, extraversion, and conscientiousness, with the age group (Table 4); also significant correlation between extraversion, and openness to experience, with the studying years at university (Table 5); and significant correlation between openness to experience and marital status (Table 6).

\section{Discussion}

Study results indicated that maximum score belonged to conscientiousness and minimum to neuroticism among the personality traits. With respect to domains of general health, maximum health deficiency was related to social dysfunction, and minimum to depression. Among 
Table 1. Descriptive data of personality traits $(n=194)$

\begin{tabular}{|c|c|c|c|c|c|}
\hline Personality Traits & Conscientiousness & Agreeableness & $\begin{array}{l}\text { Openness to } \\
\text { Experiment }\end{array}$ & Extraversion & Neuroticism \\
\hline Scores & No. (\%) & No. (\%) & No. (\%) & No. (\%) & No. (\%). \\
\hline $12-24$ & $25(12.9)$ & $40(20.5)$ & $79(40.7)$ & $60(31.0)$ & $137(70.7)$ \\
\hline $25-48$ & $169(87.1)$ & $154(79.5)$ & $115(59.3)$ & $134(69.0)$ & $57(29.3)$ \\
\hline Total & $194(100.0)$ & $194(100.0)$ & $194(100.0)$ & $194(100.0)$ & $194(100.0)$ \\
\hline Mean (SD) & $32.48 \pm 6.79$ & $29.3 \pm 5.67$ & $25.51 \pm 4.77$ & $28.08 \pm 6.85$ & $21.38 \pm 5.79$ \\
\hline Max - Min & $16-48$ & $16-48$ & $12-39$ & $12-45$ & $37-12$ \\
\hline
\end{tabular}

Table 2. Mean, standard deviation, median, minimum and maximum scores of different domains of nursing students' general health $(n=194)$

\begin{tabular}{ccccc}
\hline General Health Domains & Maximum Score & Minimum Score & Median & Mean (SD) \\
\hline Physical symptoms & 16 & 1 & 5 & $5.69(3.01)$ \\
Anxiety and insomnia & 19 & 0 & 5 & $5.80(3.77)$ \\
Social dysfunction & 21 & 0 & 8 & $8.72(3.42)$ \\
Depression & 21 & 0 & 1 & $3.27(4.36)$ \\
General Health & 54 & 22 & 6 & $151.90(48.23)$ \\
\hline
\end{tabular}

personality traits, extraversion, agreeableness, and conscientiousness have positive correlations, and neuroticism negative correlation with students' general health. Neuroticism maximum score belonged to age group 2123 , and maximum extraversion and conscientiousness scores belonged to freshmen and those over 27 years. Furthermore, senior students' general health scores were less than other students. Most nursing undergraduate students $(58.8 \%)$ were at desirable level of health. Mean (SD) total score of nursing students' general health was
25.70 (10.37) in Heravi et al. (2014) study. Among different domains of general health, maximum mean value belonged to social dysfunction with 8.53 , and minimum to depression with 4.11. In Rahaei et al. (2015) study, students' general health Mean (SD) score was 24.81 (13.41). Regarding the general health domain, maximum mean value belonged to social dysfunction with 8.40 and minimum to depression with 4.56 , i.e., maximum deficiency in health was related to social dysfunction. Namazi et al. (2015) study indicated that students' gen-

Table 3. The Pearson correlation coefficient for personality traits variables and nursing students' general health $(n=194)$

\begin{tabular}{ccc}
\hline & \multicolumn{2}{c}{ General Health } \\
Personality Traits & $\mathbf{r}$ & $\mathbf{P}$ \\
\cline { 2 - 3 } & -0.381 & $<0.001$ \\
\hline Neuroticism & 0.308 & $<0.001$ \\
\hline Extraversion & 0.083 & 0.249 \\
\hline Openness to experiment & 0.285 & $<0.001$ \\
Agreeableness & 0.351 & $<0.001$ \\
\hline Conscientiousness &
\end{tabular}


Table 4. Variance analysis of nursing students' personality traits with respect to their age $(\mathrm{n}=194)$

\begin{tabular}{|c|c|c|c|c|c|c|}
\hline \multirow[b]{2}{*}{ Personality Traits } & \multirow{2}{*}{$\frac{18-20}{\operatorname{Mean}(S D)}$} & \multirow{2}{*}{$\begin{array}{c}21-23 \\
\text { Mean (SD) }\end{array}$} & \multirow{2}{*}{$\begin{array}{c}24-26 \\
\text { Mean (SD) }\end{array}$} & \multirow{2}{*}{$\begin{array}{c}\leq 27 \\
\text { Mean (SD) }\end{array}$} & \multicolumn{2}{|c|}{ Variance Analysis } \\
\hline & & & & & $\mathbf{F}$ & $\mathbf{P}$ \\
\hline Neuroticism & $20.78(5.28)$ & $22.84(5.97)$ & $17.64(5.58)$ & $18.36(4.41)$ & 5.494 & 0.001 \\
\hline Extraversion & $29.62(6.43)$ & $26.57(6.94)$ & $26.86(7.52)$ & 30.91 (5.59) & 3.711 & 0.013 \\
\hline Openness to experience & $26.57(6.94)$ & $25.06(4.70)$ & $23.14(4.24)$ & $26.91(4.03)$ & 2.402 & 0.069 \\
\hline Agreeableness & $29.58(5.53)$ & $28.44(5.82)$ & $30.07(6.26)$ & $32.09(3.50)$ & 1.730 & 0.162 \\
\hline Conscientiousness & $33.29(6.16)$ & $31.16(6.88)$ & $32.43(8.76)$ & $37.64(4.82)$ & 3.783 & 0.011 \\
\hline
\end{tabular}

Client-Centered Nursing Care

Table 5. Variance analysis of nursing students' personality traits with respect to their academic year of education $(n=194)$

\begin{tabular}{|c|c|c|c|c|c|c|}
\hline \multirow{2}{*}{$\begin{array}{l}\text { Personality } \\
\text { Traits }\end{array}$} & \multirow{2}{*}{$\begin{array}{c}\text { First Year } \\
\text { Mean (SD) }\end{array}$} & \multirow{2}{*}{$\begin{array}{l}\text { Second Year } \\
\text { Mean (SD) }\end{array}$} & \multirow{2}{*}{$\begin{array}{l}\text { Third Year } \\
\text { Mean (SD) }\end{array}$} & \multirow{2}{*}{$\begin{array}{l}\text { Fourth Year } \\
\text { Mean (SD) }\end{array}$} & \multicolumn{2}{|c|}{ Variance Analysis } \\
\hline & & & & & $\mathbf{F}$ & $\mathbf{P}$ \\
\hline Neuroticism & $20.86(5.43)$ & $20.19(6.26)$ & $22.20(6.24)$ & $21.80(5.42)$ & 1.024 & 0.383 \\
\hline Extraversion & $29.71(7.27)$ & $29.52(7.36)$ & $28.18(5.72)$ & $25.55(6.50)$ & 4.254 & 0.006 \\
\hline Openness to experience & $27.18(4.42)$ & $24.19(6.11)$ & $25.94(4.20)$ & $24.16(4.25)$ & 4.987 & 0.002 \\
\hline Agreeableness & $29.77(5.51)$ & $30.42(7.05)$ & $28.86(5.60)$ & $28.38(5.00)$ & 1.119 & 0.343 \\
\hline Conscientiousness & $33.63(6.55)$ & $33.42(6.16)$ & $31.90(6.70)$ & $31.36(7.35)$ & 1.368 & 0.254 \\
\hline General health & $22.89(8.11)$ & 22.87 (8.29) & 22.76 (9.59) & $26.16(9.73)$ & 0.048 & 2.691 \\
\hline
\end{tabular}

eral health Mean (SD) score was 20.48 (10.07). General health total score showed that $66.1 \%$ of students were in perfect health level. Regarding general health, maximum mean value belonged to social dysfunction with 6.81 and minimum to depression with 3.55 , i.e. maximum deficiency in health belonged to social dysfunction.
Kouchakzadeh-Talemi et al. (2015) study on nursing students' general health reported that their general health Mean (SD) score was 20.48 (10.07) with minimum score of 3 and maximum 61 . Regarding the domains of general health, the results indicated that $78.6 \%$ of participants were at perfect health level with respect to their

Table 6. Mean, standard deviation, and results of $\mathrm{t}$-test to compare marital status with nursing students' personality traits $(\mathrm{n}=194)$

\begin{tabular}{|c|c|c|c|c|c|}
\hline \multirow{2}{*}{$\begin{array}{l}\text { Personality } \\
\text { Traits }\end{array}$} & Single & Married & \multicolumn{3}{|c|}{ Results of T-Test } \\
\hline & Mean (SD) & Mean (SD) & $\mathbf{P}$ & df & $\mathbf{T}$ \\
\hline Neuroticism & $21.55(5.73)$ & $20.95(5.96)$ & 0.516 & 192 & 0.651 \\
\hline Extraversion & $28.47(6.74)$ & 27.09 (7.09) & 0.208 & 192 & 1.262 \\
\hline Openness to experience & $26.01(4.52)$ & $24.24(5.19)$ & 0.019 & 192 & 2.356 \\
\hline Agreeableness & $29.27(5.65)$ & $29.13(5.78)$ & 0.872 & 192 & 0.161 \\
\hline Conscientiousness & $32.28(6.52)$ & $33.00(7.47)$ & 0.508 & 192 & -0.664 \\
\hline
\end{tabular}


physical status, and $73.2 \%$ with respect to anxiety and insomnia. With respect to social dysfunction, $31.7 \%$ of participants were on the verge of being unhealthy, and with respect to depression, $1.8 \%$ was in serious depression. With regard to general health score, most students $(66.1 \%)$ showed perfect health.

Starting academic life and continuing education is a critical period in individual's life normally accompanied by sudden changes in social relations and expectations. So being in such a condition usually comes with stress and worry. However, such a stress and anxiety was not seen much in our study, which can be due to some factors such as students' being native or their interest in their field of study.

In Imani et al. (2013) study, general health Mean (SD) score was 21.11 (9.99). With regard to domains of general heath, maximum score belonged to social dysfunction and minimum to depression. By examining each part of the questionnaire it became clear that $32.6 \%$ of participants showed disorders in physical symptoms, $37.9 \%$ in anxiety and insomnia, $54.7 \%$ in social dysfunction, and 17.9 in depression. Most common disorder was social dysfunction. They believed that authorities should pay more attention to students' social functions through advisory programs. Since students are future builders of the country and should have the best social function, the necessary conditions must be seriously considered and provided to make the best for students. As a result, they function better in society and be more confident.

In our study, we found a positive significant correlation between extraversion, agreeableness, and conscientiousness with general health; a negative significant correlation between neuroticism and general health; but no significant correlation between openness to experience and general health. These findings were similar to those found by Maleki et al. (2013), Lamers et al. (2012), and De Haro et al. (2013). Their results showed negative significant correlation between neuroticism and general health.

The reason for similar results is that people with neuroticism, compared to other people, experience negative events of life more and evaluate them more negatively, so they put themselves in situations that enrich their negative ideas about themselves. The more the people with neuroticism experience such conditions, the lower level of general health they are in. Personality traits of extraversion, agreeableness, and conscientiousness showed positive significant correlation with general health. Extrovert and agreeable people experience more positive aspects of life which helps them feel more satisfied.
Such extrovert and agreeable people have more friends and pass more time in friendly groups, so they have more motivations to have close relations which give them more optimistic view towards life and as a result better general health. Conscientious people are, too, motivated to finish their task efficiently which increases their chance to get more rewards and confirmations. Such a condition first brings a sense of respect and integrity for them and then gives them better general health. Personality trait of openness to experience showed no correlation to general health. The reason might be that openness to experience has a positive correlation with creativity and divergent thinking, which acts as a double-edged sword to give either satisfaction or dissatisfaction to the person.

Ahmadi, Nejatiand and Abdi (2009) in studying the relationship between general health and personality traits among teenagers found correlations between neuroticism, extraversion, openness to experience, and conscientiousness with general health, but nothing between agreeableness and general health. They found that teenagers with neuroticism personality were more subjected to poor general health because of their anxiety, and those with higher scores in personality traits such as extraversion, openness to experiment, and conscientiousness had better general health. Bakhshayesh's findings (2013) revealed significant negative correlation between neuroticism and general health among the health center staff, and positive significant correlation between extraversion and agreeableness with general health, but no relation between openness to experience and conscientiousness with general health.

Khanjani and Bahadori (2014) study indicated negative significant correlation between neuroticism and students' general health. There was also positive significant correlation between extraversion and their general health; i.e., the higher extraversion personality trait, the better general health. To explain this finding, it is possible to say that genetic predisposition prepares people with neuroticism personality to be depressed, anxious, and ready to lose their health. At the same time, they are subjected to more negative and stress-inducing events because of their negative views. On the other hand, extraversion is accompanied with positive emotions, so extrovert people see the events more positive and as a result have better general health.

One of the study limitations was failure to draw some students' cooperation to fill out the questionnaires. Students' mental states and their honesty in answering the questions provided some constraints for researchers, too. On the whole, since personality traits play critical role in general health of nursing students, it is expected that 
students' admission in this study field be done based on their personality. It is really important to know their personality traits because of all different issues concerning their mental growth, their vulnerability to different mental problems, and stressful conditions they may confront with during their job. Finally, it is suggested to conduct more studies on parameters affecting students' personality traits all over the country.

\section{Acknowledgements}

This study is part of the findings of the author's MS thesis which was done under the permission of Vice Chancellor's Office for Research of Iran University of Medical Sciences (IR.IUMS.REC.1394.9211196213). We are grateful to the students and authorities of School of Nursing and Midwifery of Qom University of Medical Sciences, and whoever helped us in conducting this study.

\section{Conflict of Interest}

The authors declared no conflicts of interest.

\section{References}

Ahmadi, K., Nejati, V., \& Abdi M., 2009. [Comparison of general health in adolescent boys and girls and its relationship with personality characteristics (Persian)]. Journal of Guilan University of Medical Sciences, 21(81), pp. 29-36.

Bakhshayesh, A. R., 2013. [The relationship between personality types and general health with job satisfaction of Yazd health center staffs (Persian)]. Journal of Payavard Salamat, 7(1), pp. 4255.

Barry, R. A., Lakey, B., \& Orehek, E., 2007. Links among attachment dimensions, affect, the self, and perceived support for broadly generalized attachment styles and specific bonds. Personality and Social Psychology Bulletin, 33(3), pp. 340-53. doi: $10.1177 / 0146167206296102$

Block, R. C. et al., 2013. International service and public health learning objectives for medical students. Health Education Journal, 72(5), pp. 530-6. doi: 10.1177/0017896912450874.

Chamorro-Premuzic, T. \& Furnham, A., 2009. Mainly openness: The relationship between the big five personality traits and learning approaches. Learning and Individual Differences, 19(4), pp. 524-9. doi: 10.1016/j.lindif.2009.06.004

De Haro, J. M., Castejón, J. L., \& Gilar, R., 2013. General mental ability as moderator of personality traits as predictors of early career success. Journal of Vocational Behavior, 83(2), pp. 171-80. doi: 10.1016/j.jvb.2013.04.001

Fortunato, V. J. \& Furey, J. T., 2009. The theory of mind time and the relationships between thinking perspective and the big five personality traits. Personality and Individual Differences, 47(4), pp. 241-6. doi: 10.1016/j.paid.2009.03.006

Ghorbani, A., et al., 2013. [Correlation between type of personality and academic achievement of nursing students in university of medical sciences Qazvin (Persian)]. Iranian Journal of Nursing Research, 8(28), pp. 68-75.

Golestanbagh, N., et al., 2016. [Investigation of correlation between personality traits and dietary habits in female students (Persian)]. Qom University of Medical Sciemces, 10(3), pp. 55-63.

Hasanpour, M., Haghdoost-Oskouie, S. F., Salsalei, M., 2005 [Critical thinking in nursing education (Persian)]. Iran Journal of Nursing, 18(41-42), pp. 7-16.

Heravi-Karimooi, M., Rejeh, N., \& Sharif Nia, H., 2014. [The relationship between nursing students' spiritual intelligence and their general health in Tehran, 2012 (Persian)]. Iranian Journal of Medical Education, 14(1), pp. 1-14.

Horney, J. A., et al., 2014. Fuelling the public health workforce pipeline through student surge capacity response teams. Journal of community health, 39(1), pp. 35-9. doi: 10.1007/s10900013-9750-5

Imani, E., et al., 2013. [Health status of nursing students of Hormozgan university of medical sciences by Goldberg's general health questionnaire-2011 (Persian)]. Bimonthly Journal of Hormozgan University of Medical Sciences, 17(4), pp. 357-64.

Khanjani, Z., \& Bahadori-Khosroshahi, J., 2014. [The prediction of general health on the basis of body image, life stress and personality characteristics (Persian)]. Knowledge and Research in Applied Psychology , 15(58), pp. 40-7.

Khansanami, S. H., et al., 2015. [The relationship between religious orientation and students' quality of life at medical sciences university of Qom (Persian)]. Journal of Sabzevar University of Medical Sciences, 22(2), pp. 282-8.

Komarraju, M., Karau, S. J., \& Schmeck, R. R., 2009. Role of the big five personality traits in predicting college students' academic motivation and achievement. Learning and Individual Differences, 19(1), pp. 47-52. doi: 10.1016/j.lindif.2008.07.001

Kouchakzadeh-Talami, S., Alizadeh, Sh., \& Namazi, A., 2015. [Assessment the relationship between emotional intelligence and general health among nursing students (Persian)]. Jundishapur Scientific Medical Journal, 6(2), pp. 139-46.

Lamers, S. M. A. et al., 2012. Differential relationships in the association of the Big Five personality traits with positive mental health and psychopathology. Journal of Research in Personality, 46(5), pp.517-24. doi: 10.1016/j.jrp.2012.05.012.

Maleki, Z., et al., 2013. [Relationship between personality traits, religiousity and happiness with general health among nursing students (Persian)]. Iran Journal of Nursing, 26(86), pp. 90-100.

McGready, J., \& Brookmeyer, R., 2013. Evaluation of student outcomes in online vs. campus biostatistics education in a graduate school of public health. Preventive Medicine, 56(2), pp. 142-4. doi: 10.1016/j.ypmed.2012.11.020

Moallemi, S., Bakhshani, N. M., \& Raghibi, M., 2011. [On the relationship between mental health, spiritual intelligence and dysfunctional attitudes in students of Systan and Baluchestan University, Southeast of Iran (Persian)]. Quart Journal Fundamental Mental Health, 3(48), pp. 702-9. 
Namazi, A., \& Alizadeh, S., 2015. [General health in nursing and midwifery students and its relationship with academic achievement (Persian)]. Journal of Nursing Education, 4(3), pp. 11-8.

Noorbala, A. A., Bagheri Yazdi, S. A., Mohamad, K., 2009. [The validiation of general health Questionaire-28asa psychiatric screening Tool (Persian)]. Hakim, 11(4), pp. 47-53.

Rahaei, Z., et al., 2015. [The relationship between demographic variables with general health and quality of life in students of Islamic Azad University, Sabzevar Branch, Iran (Persian)]. Qom University of Medical Sciences Journal, 9(10), pp. 40-7.

Sotodeh, N., et al., 2014. [Comparison of health status among junior and senior students of nursing and medicine in Semnan university of medical sciences in 2011-2012 academic years (Persian)]. Iranian Journal of Medical Education, 14(3), pp. $232-40$.

Zare', H., \& Mohammadzadeh, R., 2012. [The role of personality traits in predicting students' achievement motivation (Persian)]. Journal of Education \& Psychology. 4(1), pp. 117-138. 